\title{
Risk Tolerance: The Influence of Gender and Life Satisfaction
}

\author{
Zandri Dickason-Koekemoer, Suné Ferreira \\ North-West University, South Africa \\ 20800274@nwu.ac.za
}

\begin{abstract}
Financial managers base an investor's risk profile on their demographics and level of risk investors are willing to tolerate. Risk tolerance is often influenced by the different levels of life satisfaction that an investor experience and may differ based on the demographic composition of that investor. Demographic variables such as gender can differentiate between investors level of life satisfaction, which can ultimately affect investment decisions. As a result, the degree of life satisfaction can affect investment decisions by manipulating the level of risk that investors are willing to tolerate. Male and female investors can be categorised into different risk tolerance levels based on their satisfaction with life status. The aim of this study is to determine the risk tolerance level of male and female investors considering their level of life satisfaction. The results of this study indicated that the more unsatisfied investors are with their lives the less likely they will be to take on high-risk investments. Therefore, low life satisfaction is accompanied by a lowrisk tolerance level. Male investors had higher life satisfaction compared to female investors. Female investors were only willing to tolerate high risk when experiencing extremely low life satisfaction or extremely high life satisfaction stages.
\end{abstract}

Keywords: Risk tolerance, satisfaction with life, investors, gender, investment decisions

\section{Introduction}

An investment can ultimately be defined as the commitment of funds where consumption of funds can only be enjoyed at a later stage (Marx et al., 2013). Investors invest money to ensure value and wealth creation. Investments can only be rewarding if investors have skills and some financial knowledge, however, it can still be exciting and profitable without financial knowledge. The link between risk and reward is undeniable and should be treated with rational reactions. Risk is known as a theoretical concept; however, the risk-reward trade-off is measured by life experience (Crouhy et al., 2014). The risk-reward trade-off is unknown for the majority of investors which cause them to make investments through an investment brokerage company. These investment companies focus on maximising returns without sacrificing returns by minimising risks (Marx et al., 2013). These companies, usually with the aid of investor risk profiles (Rachev et al., 2011), profile investors before making any investment decisions. Such a risk profile consists typically out of a demographic section that includes factors such as age, gender, education, employment, income and marital status. Moreover, financial objectives divided between long term, medium term and short term goals form an integral part of these risk profiles. The investment goals specified by investors are not only determined by accepted risk levels, rather these goals are formulated by incorporating other factors such as financial security, the desired level of life satisfaction and current lifestyle (Marx et al., 2013). One of the factors that determine investment goals are known as risk levels, more commonly known as financial risk tolerance levels.

Financial risk tolerance is the amount of risk an individual is willing to tolerate when making financial decisions that can ultimately affect financial status (Grable, 2016). Selective and considerate investment decisions should be made regarding investment products and asset allocation. The variables that can possibly influence the level of risk tolerance are important to investigate as it can influence investment choices. One of the variables that can influence the risk tolerance levels is gender. Looking at previous research conducted, it is still not universally agreed upon whether gender differences can have an influence on risk tolerance levels. Grable and Lytton, (1998) concluded in their research that age and gender are regarded as the most important influences on risk tolerance levels. In contradiction to the above, Grable and Joo, (2000) found gender, age and marital status to be insignificant towards risk tolerance. Researchers such as Higbee and Lafferty (1972), Blume (1978), Coet and McDermott (1979), Rubin and Paul, (1979) and Yip, (2000) considered the gender factor to be significant towards contemplating investor risk tolerance. An accord was reached between these researchers that male investors take more risk compared to female investors. Slovic, (1966) stated that from a cultural perspective, that males take more risk than females, thus males are more 
risk tolerant compared to females. However, this viewpoint that males are more risk tolerant compared to females are not commonly accepted (Yip, 2000; Marinelli et al., 2017).

Also, researchers such as Hanna et al. (1998) and Grable and Joo, (2004) found in their research no evidence of a relationship between gender and risk tolerance. Despite the fact that international studies such as Grable and Joo (2000), Higbee and Lafferty (1972), Blume (1978), Coet and McDermott (1979), Rubin and Paul, (1979) and Yip, (2000) have investigated the factors that influence investment decisions, research within the South African context is still absent. Research within investment companies is necessary to assist financial planners to accurately identify the factors that may influence their client's financial risk tolerance and ultimately the performance of their portfolios. Therefore, the objective of this paper is to identify whether demographic factors such as gender and life satisfaction influence an investors risk tolerance level.

\section{Literature Review}

Investors, just like any other individual, strive to understand what is meant by a good life. Diener, (2000) stated that in terms of social sciences, a good life includes factors such as financial stability, pleasure, affection from others and self-insight. Subjective well-being is a specific measurement tool that measures satisfaction with life (SWL) based on the perceptions of personal life experiences of individuals. Diener, (2000) regarded perceptions to be a more accurate measure of actual feelings and thus can be regarded as a direct measure of actual experiences. Investors tend to be more satisfied with their life when experiencing more pleasant than unpleasant emotions in terms of investment activities (Diener, 2000). The quality of life of an investor tends to be increased when positive emotions are experienced regarding good investment choices. As soon as deviations exist between the current level of life satisfaction and the desired level of life satisfaction, potential investment decisions may be influenced. Investment choices of investors are based on the suggestions of an investment company. However, these profiles do not indicate which investment was chosen by the investor (Mayo, 2000).

Thus, individual investors and investment companies should take into account the consequence SWL could potentially have on investment decisions. Diener, (2009) highlighted that if individuals are deemed happy, they are happy in almost all areas of their lives. Moreover, if an individual seeks approval and experience unhappiness most of the time, the individual is deemed to be unsatisfied in most areas of his/her life. Typically, such individuals will take active steps to experience happiness in order to improve their SWL status. If the SWL status is already negative, individuals tend to be more pessimistic and reluctant to put in efforts to improve financial situations (Diener et al., 1991). Confirmed in their research that demographic factors, such as age, health and financial status have an influence on the overall well-being of the individual moreover, any changes in these factors can have an influence on the SWL status of the individual. In terms of gender, it was found by Shirazi and Khan, (2013) that males tend to be more satisfied with life than females. Glenn, (1975) concluded in research conducted that married males presents more happiness and higher life satisfaction status than widowed, divorced, separated or never married males.

Moreover, it was also concluded that married females display only a little more happiness compared to unmarried females. Also, married men tend to have a greater SWL status than married females. Investment goals are formulated by accepted risk levels, financial security, the desired level of life satisfaction and current lifestyle mix (Marx et al., 2013). The linkage between well-being and social capital can be found and those linkages may be direct or indirect (Helliwell, 2003). A better quality of life is offered by present good conditions as well as good financial prospects along with monetary security. People who are more satisfied with their lives are those with job security, higher financial stability, higher monthly income and quality financial management (Diener, 2012). These individuals will be more willing to tolerate risk. In contrast, poor people lack enough resources that can enable them to have an income that could impact their lives in a meaningful way whereby this will result in lower life satisfaction accompanied by lower levels of risk tolerance (Meyer \& Dunga, 2014). 


\section{Methodology}

Research Purpose and Design: The overriding objective of this research study was to conclude whether the SWL of investors influences the risk tolerance levels of male and female investors. As a result, a positivistic world view was adopted, typically associated with a quantitative study (Goulding, 2005; Creswell \& PlanoClark, 2011).

Research Instrument: In order to measure, the risk tolerance level of participants, a validated risk tolerance question was used which consists of a single risk tolerance question. Various researchers use the Survey of Consumer Finance (SCF) because this question directly measures the risk attitude of participants (Gilliam et al., 2010). Participants' happiness was evaluated with the aid of a self-reporting measure. The perception of participants is captured by assigning a numeric score to the participants' quality of life. A comment was made by Baird et al. (2010) that if the scoring system is accurate, this scale is regarded feasible in terms of accounting for a large section between participants' variation in self-assessed well-being by using demographic variables. A seven-point Likert scale was used to rate the life satisfactions statements which ranged from (1) strongly disagree to (7) strongly agree. The five-factor SWL scale (derived from 48 items) focus on emotional as well as judgemental aspects.

Research Sample: The research population of this paper consisted of all investors in South Africa, over the nine provinces whereby a financial investment company granted permission to gather online information from their clientele. A purposeful sample was selected as investors were specifically chosen for this study. A sample of 800 participants $(n=800)$ participated in an online questionnaire out of own free will. The selected sample meets the requirements of the statistical analysis that was applied to achieve the stated objective of this paper.

Hypothesis: The following hypotheses were formulated to research the primary objective of this study: Null hypothesis $\left(\mathrm{H}_{01}\right)$ : investor gender does not influence investor risk tolerance.

Null hypothesis $\left(\mathrm{H}_{01}\right)$ : investor satisfaction with life does not influence investor risk tolerance.

The null hypotheses state there are no differences between the risk tolerance of investors based on their gender and life satisfaction.

Statistical Analysis: Despite the use of descriptive statistics such as cross-tabulations, logistic binary regression was also used to test how SWL and gender influence the risk tolerance level of investors.

$S C F_{i}=\emptyset_{0}+\emptyset_{1} G E N+\emptyset_{2} S W L+\varepsilon_{i}$

The dependent variable $S C F_{i}$ was created using the SCF scale explained in the methodology. $S C F_{i}$ Represent dichotomous dependant variable that was created using the mean value of the scale - the risk tolerance level of investors ( 0 for low risk tolerance and 1 for high risk tolerance). The variable $\emptyset_{0}$ give the constant, $\emptyset_{1} \emptyset_{2}$ are the estimated coefficients while $\varepsilon_{i}$ represents the error term. Two independent variables were created $\emptyset_{1} G E N$ was given as the gender of investors (1=males, $0=$ female) and $\emptyset_{2} S W L$, shows the life satisfaction of investors; (1=extremely dissatisfied, $2=$ dissatisfied, $3=$ below average life satisfaction, 4=average life satisfaction, $5=$ high life satisfaction, $6=$ highly satisfied).

\section{Empirical Results}

Demographical Background of Participants: The descriptive statistics indicate that 56.1 percent of the participants were female investors while 43.9 percent were male investors. The results suggest that 5 percent of the investors were extremely dissatisfied with their lives while 13 percent were dissatisfied. Almost 16 percent of investors were just below the average life satisfaction whereas 23.5 percent had an average SWL. The majority of investors (28.4\%) indicated that they have a high SWL and 14.5 percent indicated that they are highly satisfied with their lives. The mean value of 4.01 indicated that the majority of investors within this sample have an average life satisfaction.

Investor Risk Tolerance According to SWL: Table 1 indicates the cross-tabulation of the investors level of risk tolerance based on investors life satisfaction according to males and females. 
Table 1: Gender Satisfaction with Life and Risk Tolerance

\begin{tabular}{lllll}
\hline \multirow{2}{*}{ Variable (SWL) } & Category & $\begin{array}{c}\text { Risk tolerance level } \\
\text { Low }\end{array}$ & $\begin{array}{c}\text { High risk } \\
\text { tolerant }\end{array}$ & Pearson Chi-square \\
\hline \multirow{2}{*}{ Extremely dissatisfied } & Male & $93.3 \%$ & $6.7 \%$ & $0.038^{* *}$ \\
& Female & $64.0 \%$ & $36.0 \%$ & $(4.302)$ \\
Dissatisfied & Male & $46.5 \%$ & $53.5 \%$ & $0.005^{* * *}$ \\
Slightly below average & Female & $73.8 \%$ & $26.2 \%$ & $(7.996)$ \\
satisfaction & Male & $64.7 \%$ & $35.3 \%$ & 0.622 \\
Average life satisfaction & Female & $68.9 \%$ & $31.1 \%$ & $(0.243)$ \\
& Male & $57.1 \%$ & $42.9 \%$ & $0.004^{* * *}$ \\
High life satisfaction & Female & $76.9 \%$ & $23.1 \%$ & $(8.367)$ \\
& Male & $58.7 \%$ & $41.3 \%$ & $0.024^{* *}$ \\
Highly satisfied & Female & $72.9 \%$ & $27.1 \%$ & $(5.073)$ \\
& Male & $44.9 \%$ & $55.1 \%$ & $0.026^{* *}$ \\
\hline
\end{tabular}

${ }^{*}$ significant at $<0.10 ;{ }^{* *}$ significant at $<0.05 ;{ }^{* * *}$ significant at $<0.01$

Table 1 categorises investor risk tolerance levels (low risk tolerant or high risk tolerant) in light of their gender and level of SWL. The life satisfaction of investors was divided into six categories, ranging from the lowest SWL to the highest SWL. In view of gender, the Pearson Chi-Square value of 4.302 and the p-value of 0.038 indicate a statistical difference between the risk tolerance levels of male and female investors with an extremely dissatisfied SWL. Results further indicate that male investors who have an extremely dissatisfied SWL (93.3\%) are low risk tolerant while 6.7 percent of males are high risk tolerant. This is in comparison with the female investors from whom 64.0 percent were low risk tolerant and 36.0 percent were high risk tolerant. Within the extremely dissatisfied SWL category female investors were slightly more willing to tolerate higher risk than male investors. Considering the dissatisfied SWL category, more female investors were perceived to be low risk tolerant (73.8\%) while only a quarter of them were willing to take on higher risk. Within this category more than half of the males $(53.5 \%)$ were high risk tolerant while the remaining $(46.5 \%)$ were low risk tolerant. A shift in the risk tolerance between males and females can be seen between the extremely dissatisfied category where females were more willing to take on higher risk $(36.0 \%$ compared to $6.7 \%$ of males) and the dissatisfied SWL category where male (53.5\% compared to females $26.2 \%$ ) are now more willing to take on higher risk.

This proves again that males are more risk tolerant than females and those females will only take on higher risk during extreme cases such as being extremely dissatisfied with life. These results are similar to Slovic, (1966), Sung and Hanna (1996), Sharma (2006) and Rahmawati et al. (2015) who reached a consensus that females take less risks than males, thus males are more risk tolerant than females. No statistical difference exists in gender risk tolerance of investors within the slightly below average SWL. More than 60 percent of male and females within this category were low risk tolerant while the remaining percentage of male and female, investors were high risk tolerant. On the other hand, a statistical difference existed between gender risk tolerance for the average SWL category. The bulk of female investors $(76.9 \%)$ who have an average SWL were low risk tolerant while more than 40 percent of the male investors who have an average SWL were high risk tolerant. In the high and highly SWL category the positive relationship can be seen between a high SWL and a high-risk tolerance level. The risk tolerance levels for males $(41.3 \%)$ in the high SWL category and females $(24.1 \%)$ showed an upward trend in the highly satisfied category for both male investors (44.9\%) and female investors $(34.3 \%)$.

Binary Logistic Regression Results: Table 2 indicates the results found for the logistic regression in terms of the influence of gender SWL on risk tolerance considering South African investors. 
Table 2: Binary Logistic Regression of Investor Life Satisfaction and Gender with in Risk Tolerance

\begin{tabular}{|c|c|c|c|c|c|c|c|}
\hline Variable & Beta & $\begin{array}{l}\text { Std. } \\
\text { Error }\end{array}$ & Wald & DF & Sig. & $\operatorname{Exp}(B)$ & Odds ratio \\
\hline Gender (Male) & 0.647 & 0.151 & 18.220 & 1 & $0.000^{* * *}$ & 1.909 & 0.909 \\
\hline \multicolumn{3}{|l|}{ Highly satisfied } & 6.763 & 5 & 0.239 & & \\
\hline $\begin{array}{l}\text { Extremely } \\
\text { dissatisfied }\end{array}$ & -0.808 & 0.415 & 3.798 & 1 & $0.051^{*}$ & 0.446 & 0.554 \\
\hline Dissatisfied & -0.233 & 0.279 & 0.696 & 1 & 0.404 & 0.792 & 0.208 \\
\hline $\begin{array}{l}\text { Slightly below } \\
\text { average life } \\
\text { satisfaction }\end{array}$ & -0.441 & 0.271 & 2.655 & 4 & 0.103 & 0.644 & 0.356 \\
\hline $\begin{array}{l}\text { Average life } \\
\text { satisfaction }\end{array}$ & -0.508 & 0.247 & 4.218 & 1 & $0.040^{* *}$ & 0.602 & 0.398 \\
\hline High life & -0.437 & 0.237 & 3.388 & 1 & $0.066^{*}$ & 0.646 & 0.354 \\
\hline Constant & -0.557 & 0.201 & 7.660 & 1 & $0.006^{* * *}$ & 0.573 & \\
\hline \multicolumn{3}{|c|}{-2 Log likelihood 1007.240} & \multicolumn{4}{|c|}{ Omnibus Test 24.911} & Beta \\
\hline $\begin{array}{l}\text { Hosmer \& Lemes } \\
\text { Nagelkerke R-sq }\end{array}$ & $\begin{array}{l}\text { w } 5.761 \\
\text { red } 0.042\end{array}$ & & \multicolumn{4}{|c|}{ P-value 0.000} & -0.636 \\
\hline
\end{tabular}

The Omnibus test for model coefficients represented in Table 2 indicates that the test was significant at 1 percent with a Chi-square value of 24.911. Consequently, the model is significantly better and passed the goodness fit model concerning the Hosmer \& Lemeshow test obtained a p-value of 0.568. The Nagelkerke Rsquared test as indicated in Table 2 also recommends that the model coefficients explain 4.2 percent of the variation in investor satisfaction with life. This value is considerably low and can be attributed to the low number of independent variables. The negative beta value $(-0.636)$ for the equation suggests that an inverse relationship exists between the dependant and independent variables the more unsatisfied investors are with their lives the less likely they will be to take on high risk. Hence, the results would suggest that low life satisfaction indicates low levels of risk tolerance. Considering the first independent variable, gender, male investors are more likely to be highly satisfied with their lives compared to female investors since a positive coefficient (0.647) was observed.

The p-value smaller than 0.1 for gender suggests that gender has a significant influence on the risk tolerance level of investors. Therefore, the alternative hypothesis was concluded. The odds ratio (1.909-1) suggests that male investors in South Africa are 90 percent more likely to be risk aggressive compared to female investors in South Africa. Considering investors life satisfaction, those who are extremely dissatisfied with their lives are less likely to be high risk tolerant since a negative coefficient $(-0.808)$ was obtained. As a result, the alternative hypothesis can be concluded. The odds ratio suggests that investors who are extremely dissatisfied with their lives are 55.4 percent less likely to be high risk tolerant with a p-value of 0.051 significant at the 10 percent level. Investors who are dissatisfied with their lives were only 20.8 percent less likely to be high risk tolerant $(-0.233)$ due to the negative coefficient observed. This is similar to Statman, (2015) who found people who are unsatisfied with their lives tend to tolerate more risk (such as gambling) and try new things.

For investors who have a below average SWL where a negative coefficient was also observed (-0.441). Investors who have a below average SWL are 35.6 percent less likely to be high risk tolerant than investors who are highly satisfied with their lives. However, the statistical difference proofed not to be significant (pvalue of 0.103 ). For investors who have an average life, satisfaction was found to be 38.9 percent less likely to be high risk tolerant than those investors that are highly satisfied with their lives. This was proved to be significant at the 5 percent confidence level with a p-value of 0.04. Investors that have a high SWL were found to be only 35.4 percent less likely to be high risk tolerant than those investors who are highly satisfied with their lives. Previous researchers suggest that more satisfied people tend to be less risk averse and are willing to take on higher risk since they have already achieved their desired level of life satisfaction (Weber, 2013). 


\section{Conclusion}

The overriding objective of this research study was to conclude whether the SWL of investors influences the risk tolerance levels of male and female investors. The literature of this study revealed that the risk tolerance of investors is influenced by demographics and behavioural finance decisions. However, the results also indicate that SWL contributes a great deal to the risk tolerance of investors. It is therefore recommended that financial advisers, portfolio managers and investment companies take the investors SWL into account when constructing the risk profile of the investor. The results of this research study proved similar results of previous studies which found that male investors have an overall higher risk tolerance level compared to female investors. The study also revealed that female investors will only be willing to tolerate more risk in extreme situations such as when they are extremely dissatisfied with their life or when highly satisfied with their life. In terms of investment, this indicates that female investors will only take risky financial decisions or invest in risky assets either when they are extremely dissatisfied with their life or extremely satisfied with their life. The study further exemplified the positive relationship between the SWL of investors and the level of risk they are willing to take.

The binary logistic regression indicated that the more dissatisfied investors are with their lives the less willing they will be to take on high-risk investment. As a result, low SWL influences low-risk tolerance levels of investors whereas high SWL influences high-risk tolerance levels of investors. This will significantly contribute towards the risk profiling of investors to accurately invest according to a specific risk tolerance level. Future recommendations are that researchers can make use of a more complex structural equation model (SEM) in order to integrate more variables such as a complete demographic composition of investors and behavioural finance to assist in the creation of a comprehensive structural investor profile. Future studies can also make use of a more condensed sample focusing on one of the nine provinces in South Africa.

\section{References}

Baird, B., Lucas, R. \& Donnellan, M. (2010). Life satisfaction across the lifespan: findings from two nationally representative panel studies, $N C B I, 99(2), 183-20$.

Blume, M. (1978). The changing role of the individual investor. New York: John Wiley \& Sons.

Coet, L. J. \& McDermott, P. J. (1979). Sex, instructional set, and group make-up: orgasmic and situational factors influencing risk-taking. Psychological Reports, 44(1), 1283-1294.

Creswell, J. W. \& Plano-Clark, V. L. (2011). Designing and conducting mixed research methods. California: SAGE.

Crouhy, M., Galai, D. \& Mark, R. (2014). The essentials of risk management. 2nd Ed. New York, NY: McGrawHill Education.

Diener, E. \& Ryan, K. (2009). Subjective well-being: a general overview. South African Journal of Psychology, 34(9), 391-406.

Diener, E. (2000). Subjective well-being: the science of happiness and a proposal for a national index. American Psychologist, 55(1), 34-43.

Diener, E., Sandvik, E. \& Pavot, W. (1991). Happiness is the frequency, not the intensity, of positive versus negative effect. (In F. Strack, M. Argyle, \& N. Schwarz (Eds.), Subjective well-being: An interdisciplinary perspective (pp. 119-139). New York: Pergamon).

Diener, E. (2012). New findings and future directions for subjective well-being research. American Psychologist, 67(8), 590-597.

Gilliam, J., Chatterjee, S. \& Grable, J. E. (2010). Measuring the perception of financial risk tolerance: a tale of two measures. Journal of Financial Counselling and Planning, 21(2), 30-43.

Glenn, N. D. (1975). The contribution of marriage to the psychological well-being of males and females. Journal of marriage and family, 37(3), 594-600.

Goulding, C. (2005). Grounded theory, ethnography and phenomenology. European Journal of Marketing, $3(39), 294-308$.

Grable, J. E. (2016). Financial risk tolerance. Switzerland: Springer.

Grable, J. E. \& Joo, S. (2000). A cross-disciplinary examination of financial risk tolerance. Consumer Interests Annual, 46(2), 151-157. 
Grable, J. E. \& Joo, S. (2004). Environmental and biopsychosocial factors associated with financial risk tolerance. Journal of Financial Counselling and Planning, 15(1), 73-82.

Grable, J. E. \& Lytton, R. H. (1998). Investor risk tolerance: testing the efficacy of demographics as differentiating and classifying factors. Financial Counselling and Planning, 9(1), 61-73.

Hanna, S., Gutter, M. \& Fan, J. (1998). A theory based measure of risk tolerance. Proceedings of the Academy of Financial Services, 12(1), 10-11.

Helliwell, J. F. (2003). How's life? Combining individual and national variables to explain subjective wellbeing. Economic Modelling, 20(2), 331-360.

Higbee, K. L. \& Lafferty, T. (1972). Relationships among risk preferences, importance, and control. The Journal of Psychology, 81(1), 249-251.

Marinelli, N., Mazzoli, C. \& Palmucci, F. (2017). How does gender really affect investment behaviour? Economic Letters, 151(3), 58-61.

Marx, J. (2013). Investment Management. 4rd ed. Hatfield, Pretoria: Van Schaik.

Mayo, M. (2000). Investments: An Introduction. 6th ed. Orlando, FL: Harcourt.

Meyer, D. F. \& Dunga, S H. (2014). The determinants of life satisfaction in a low-income, poor community in South Africa. Mediterranean Journal of Social Sciences, 5(13), 163-171.

Rachev, S. T., Stoyanov, S. V. \& Fabozzi, F. J. (2011). Risk and uncertainty. Hoboken, N.J.: John Wiley and Sons Inc.

Rahmawati, M., Kumar, D., Kamuaya, M., Jamil, F. \& Muneer, S. (2015). Determinants of the risk tolerance of individual investors. International Journal of Economics and Financial Issues, 12(1), 373-378.

Rubin, P. H. \& Paul, C. W. (1979). An evolutionary model of tastes for risk. Economic Inquiry, 17(4), 585-596.

Sharma, K. (2006). An insight into determinants of financial risk tolerance. SCMS Journal of Indian Management, 11(3), 12-23.

Shirazi, M. \& Khan, M. A. (2013). Life satisfaction among professional and non-professional students in India. International Journal of Applied Psychology, 3(4), 109-113.

Slovic, P. (1966). Risk-taking in children: age and sex differences. Child Development, 37(4), 169-176.

Statman, M. (2015). Culture in risk, regret, maximization, social trust, and life satisfaction. Journal of Investment Consulting, 16(1), 20-30.

Sung, J. \& Hanna, S. (1996). Factors related to household risk-tolerance: an ordered probit analysis. Consumer Interests Annual, 42(2), 227-228.

Weber, C. (2013). Cultural differences in risk tolerance. Working paper, 01. Erlangen. May.

Yip, U. Y. (2000). Financial risk tolerance: a state or a trait? University of New South Wales. (Thesis-Masters). 